Volume 3

Issue 1 The Syriac Galen Palimpsest

Article 2

5-9-2019

\title{
Pulling It All Together: Managing the Syriac Galen Palimpsest Project
}

Michael Toth

R.B. Toth Associates, mbt.rbtoth@gmail.com 


\title{
Pulling It All Together: Managing the Syriac Galen Palimpsest Project
}

\author{
Abstract \\ During a two-year period, from 2009 to 2010, a multidisciplinary team conducted multispectral imaging, \\ digital processing and data management of the Syriac Galen Palimpsest. This contractor-led team applied the \\ turnkey multispectral imaging techniques developed in earlier advanced imaging projects to this palimpsest. \\ This required new management techniques and work processes to provide useful results efficiently and \\ quickly, while minimizing risk. In the initial risk-mitigation study phase, the team first imaged several leaves of \\ the bound SGP in 2009 to characterize the imaging and processing challenges. Building on the findings from \\ this first phase, they then imaged all the disbound leaves in 2010. Management of the SGP imaging and \\ processing focused on integration of the people, processes and technology into an efficient imaging system. \\ This included planning and managing the data flow, data replication, image processing and production of the \\ image product while avoiding bottlenecks. With over $300 \mathrm{~GB}$ of data hosted for open access, this project \\ provided opportunity for further study and collaboration, and multispectral imaging work processes used on \\ subsequent programs. This access to the online images allowed a global team of scholars to conduct \\ independent research, during which they also discovered leaves missing from the bound manuscript.
}

\section{Keywords}

Galen, multispectral imaging, risk mitigation, program management, work processes, systems integration, palimpsest 


\section{MANUSCRIPT STUDIES}

A Journal of the Schoenberg Institute for Manuscript Studies

VOLUME 3, NUMBER 1

(Spring 2018)

Manuscript Studies (ISSN 2381-5329) is published semiannually

by the University of Pennsylvania Press

The Schoenberg Institute
for Manuscript Studies
University of Pennsyivania Libraries 


\section{MANUSCRIPT STUDIES}

A Journal of the Schoenberg Institute for Manuscript Studies

VOL UME 3, N U M B E 1

Special Issue:

The Syriac Galen Palimpsest

Editors: William Noel and Ralph M. Rosen

\section{Articles}

The Syriac Galen Palimpsest Project: An Introduction

William Noel and Ralph M. Rosen

Pulling It All Together: Managing the Syriac Galen

Palimpsest Project

Michael B. Toth

The Codicology and Conservation of the Syriac

Galen Palimpsest

Abigail B. Quandt and Renée C. WolcotT

Spectral Imaging Methods Applied to the Syriac

Galen Palimpsest

Roger L. Easton, Jr., Keith T. Knox, William A. Christens-Barry, AND Ken Boydston

The Galen Palimpsest and the Modest Ambitions of the

Digital Data Set

Doug EMERY

The Syriac Galen Palimpsest: A Tale of Two Texts

Naima Afif, Siam Bhayro, Grigory Kessel, Peter E. Pormann,

William I. Sellers, and Natalia Smelova 
iv | Journal for Manuscript Studies

Analyzing Images, Editing Texts: The Manchester Project

Naima Afif, Siam Bhayro, Peter E. Pormann, William I. Sellers, and Natalia Smelova

The Textual Interest of the Syriac Versions of Galen's Simples

Irene Calà, Jimmy Daccache, and Robert Hawley 186

\section{Annotations}

Of Scribes and Scripts: Citizen Science and the Cairo Geniza

Preserving Endangered Archives in Jerba, Tunisia:

The al-Bāsī Family Library Pilot Project

Ali Boujdidi And Paul M. Love

The Intricacies of Capturing the Holdings of a Mosque

Library in Yemen: The Library of the Shrine of Imām alHādī, Șa da

SABINe SchmidtKe

Compilation, Collation and Correction in the Time of Encyclopedism: The Case of UPenn LJS 55

Nathalie Lacarrière

Mapping Manuscript Migrations: Digging into Data for the History and Provenance of Medieval and Renaissance

Manuscripts

Toby Burrows, Eero Hyvönen, Lynn Ransom, and Hanno Wijsman

\section{Reviews}

Ahmad 'Abd al-Bāsiṭ. Catalogue of the Private Collections of

Manuscripts in the Egyptian National Library

ELIAS G. SABA 
iv | Journal for Manuscript Studies

Analyzing Images, Editing Texts: The Manchester Project

Naima Afif, Siam Bhayro, Peter E. Pormann, William I. Sellers,

and Natalia Smelova

The Textual Interest of the Syriac Versions of Galen's Simples

Irene Calà, Jimmy Daccache, and Robert Hawley 186

\section{Annotations}

Of Scribes and Scripts: Citizen Science and the Cairo Geniza

Laura Newman Eckstein

Preserving Endangered Archives in Jerba, Tunisia:

The al-Bāsī Family Library Pilot Project

Ali Boujdidi And Paul M. Love

The Intricacies of Capturing the Holdings of a Mosque

Library in Yemen: The Library of the Shrine of Imām alHādī, Șa da

Sabine Schmidtke

Compilation, Collation and Correction in the Time of Encyclopedism: The Case of UPenn LJS 55

Nathalie Lacarrière

Mapping Manuscript Migrations: Digging into Data for the

History and Provenance of Medieval and Renaissance

Manuscripts

Toby Burrows, Eero Hyvönen, Lynn Ransom, and Hanno Wijsman

\section{Reviews}

Ahmad 'Abd al-Bāsiṭ. Catalogue of the Private Collections of

Manuscripts in the Egyptian National Library

ELIAS G. SABA 
Toth: Pulling It All Together: Managing the Syriac Galen Palimpsest Pro

Contents | v

David T. Gura. A Descriptive Catalogue of the Medieval and Renaissance Manuscripts of the University of Notre Dame and Saint Mary's College

Lisa FAgin Davis 256

Christopher De Hamel. Meetings with Remarkable Manuscripts

DANiel Traister 260 
Manuscript Studies, Vol. 3 [2019], Iss. 1, Art. 2 


\title{
Pulling It All Together \\ Managing the Syriac Galen Palimpsest Project
}

\author{
Michael B. Тотн \\ R. B. Toth Associates
}

I

F the Archimedes Palimpsest program was like a long-term National Aeronautics and Space Administration (NASA) research and development program, the Syriac Galen Palimpsest project was like a SpaceX program to quickly design and launch a spacecraft. This multispectral imaging project required application of different management techniques and work processes to provide useful results efficiently and quickly, while minimizing risk.

From 1998 to 2008, during the Archimedes Palimpsest program, a multidisciplinary team conducted multispectral imaging experiments; developed new illumination, imaging, and processing techniques; and utilized their findings to digitize and support scholars' studies of the erased texts in the Archimedes Palimpsest. Program director Will Noel, conservator Abigail Quandt, and program manager Michael B. Toth organized a team of contractors and institutional partners who worked for the Walters Art Museum in a long-term research and development program. These included imaging scientists Bill Christens-Barry, Roger Easton, and Keith Knox, and data manager Doug Emery. This was funded on an annual basis by the owner of the palimpsest. Since digitization of historic manuscripts was at that time still a developing field, the program applied established program management techniques from other fields, and developed new data management techniques and metadata standards specific to the needs of the project. 
Following the decade-long imaging effort, all the Archimedes Palimpsest spectral image data and transcriptions were released online in 2008. The scholars, scientists, and other team members also published their results in articles and books and supported an exhibition at the Walters Art Museum and Huntington Library.

From 2009 to 2010, during the Syriac Galen Palimpsest (SGP) project, a similar multidisciplinary team imaged the entire SGP over a two-year period. The owner fully funded this project, but on a firm fixed price contract for each of the two imaging sessions. Toth served as the prime contractor to the Walters as the team applied what had become turnkey multispectral imaging techniques developed in earlier projects. The SGP project was able to apply the mature Archimedes Palimpsest Metadata Standards for the image data and metadata. As was done with the Archimedes Palimpsest image data and metadata, the SGP project hosted all 300 GB of image data online for free, global access under Creative Commons license.

Interest and research into ancient medical practices and the transfer of information about these practices brought Siam Bhayro, Robert Hawley, Grigory Kessel, Peter Pormann, and other scholars from across Europe together in an independent study of the SGP. Representing academic institutions in England, France, and Germany, they built on Siam Bhayro and Sebastian Brock's initial work during the multispectral imaging to highlight new texts in the SGP after completion of the imaging and processing.

The academic study began with online collaboration, followed by the first face-to-face workshop at the University of Manchester in May 2012, which also included Jimmy Daccache, John Healey, and Michael Toth. In 2013 they published a summary report on their initial findings from the SGP, highlighting Galen's treatise On the Mixtures and Powers of Simple Drugs (or just On Simple Drugs). Their work and that of others led to additional imaging of the missing leaves and continued research of the original image data and that from the additional imaging. Research supported by tailored imaging continues through publication of this journal, in which other team members provide more details of each of the components of the SGP project. 
Like the Archimedes Palimpsest before it, the SGP builds on the work of internet pioneers, NASA, and the National Institute of Standards and Technology for guidance and standards use to support digital preservation, free access, and sharing of standard data. The SGP project team capitalized on developed standards, protocols, and work processes to address challenges in storing, moving, and visualizing large digital images and data sets and ensure the preservation of the digital SGP for future generations. To address challenges in bringing together multiple disciplines and technologies into a successful program, it also capitalized on program management practices refined from those used for information technology, aerospace, and technology development.

\section{Program Management}

Successful completion of complex technical programs like the SGP Multispectral Imaging Project within budget, on schedule, and to the required levels of performance requires effective planning and management. This is particularly true for programs like these that require the support of personnel from diverse work cultures working with different technologies and multiple work processes. Despite their different backgrounds and fields of expertise, all these people need to collaborate to reach successful conclusions with a quality product. While digitization tends to focus on integrating the technology used to gather the images, success is really dictated by the integration and management of the people on the team and efficient work processes, as well as the technologies.

With the advent of digitization for cultural heritage and digital humanities programs, effective planning and management have required the adoption of techniques and skills used in information technology, aerospace, and other industries implementing technical programs. Since museums, libraries, and academia have very different cultures, these techniques cannot be just adopted wholesale. Schedule, cost, and performance have a different impact in institutions with roots in the more freewheeling and independent academic and scientific environments. This requires not only application of 
appropriate program management and planning tools, but also focused meetings, status reports, and metrics to be able to assess the progress and issues of a diverse team working with a variety of technologies.

In planning and managing the SGP project, the team took a full lifecycle approach to the information captured from the object. Effective digitization programs-including multispectral imaging of the SGP-must include not just the capture of pictures, but also the generation of metadata, image processing, data integration and hosting, and finally that sharing and access that needs to continue long after the completion of the project. The resulting data set must meet international data, metadata, and integrity standards that will provide long-term preservation and access. ${ }^{1}$ Accomplishing this requires planning and management of not just individual technologies and skills, but also the effective management of the end-to-end tasks and workflow: from capturing standardized data and metadata to making it available to online end users (fig. 1).

While it is true that one size does not fit all, the Archimedes and Galen Palimpsest imaging projects did proceed through the same stages of work as most technical development programs: ${ }^{2}$

- Initiation: Establishing the project or phase.

- Planning: Defining a plan, refining objectives, and selecting the best of the alternative courses of action to attain the objectives of the project.

- Execution: Coordinating people and other resources to carry out the plan.

- Control: Ensuring the project objectives are met by collecting metrics regularly to measure progress and identify variances from the plan so that corrective action can be taken when necessary.

1 M. B. Toth, "How Do We Preserve and Share Our Digital Library Information?," in What Do We Lose When We Lose a Library? Proceedings of the Conference Held at KU Leuven 9-11 September 2015, ed. M. Collier (2016), 207-13.

2 Some program managers use a six-step process. Others use a five-step process. This author uses the latter, highlighting the need for a tailored approach to program management. 


\section{Spectral Imaging Program \& Data Management End-to-End Workflow}

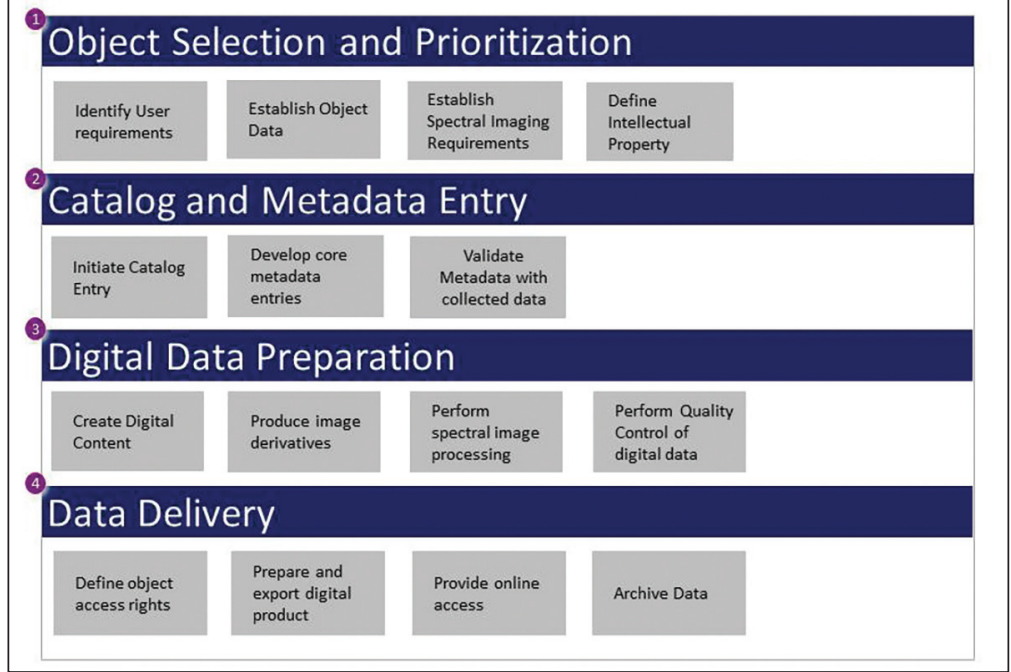

FIGURE 1. Multispectral imaging workflow.

- Closeout: Formalizing acceptance of the project or phase and its products and bringing it to an orderly end or transition to another organization.

\section{Initial Multispectral Imaging Study}

While the owner has not documented his reasoning for supporting the Archimedes and Galen multispectral imaging efforts, Will Noel noted in April 2012:

[The owner] wanted to make that which was unique ubiquitous. He wanted to make that which was expensive free. And he wanted to do this as a matter of principle. ... Why did the owner of the manuscript do this? He did this because he understands data as 
well as books. Now the thing to do with books, if you want to ensure their long-term utility, is to hide them away in closets and let very few people look at them. The thing to do with data, if you want it to survive, is to let it out and have everybody have it with as little control on that data as possible. And that's what he did. ${ }^{3}$

With the owner's decade-long support, the Archimedes Palimpsest program tapped advanced imaging capabilities developed by the image scientists to glean important new information about the undertexts in the palimpsest. The imaging team conducted narrow-band multispectral imaging in a dark room with illumination sequenced through specific spectral bands provided by light-emitting diodes. With post-processing of the images, this narrow-band multispectral imaging was successful in revealing not only more Archimedes text, but also completely new texts from the ancient world. As a result, these multispectral imaging techniques have subsequently been employed with continued development and adaptation in other programs. ${ }^{4}$

At the instigation of the owner, William Noel, then curator of manuscripts at the Walters Art Museum, asked for a proposal from R. B. Toth Associates for multispectral imaging of the SGP. Michael Toth in turn collaborated with the imaging team from the Archimedes Palimpsest Program: image scientists Bill Christens-Barry, Roger Easton, and Keith Knox; conservator Abigail Quandt; and data manager Doug Emery. With the support of camera engineer Ken Boydston and others, the team further developed narrow-band multispectral imaging, illumination and processing technologies, work processes, and data management that could be applied to multispectral imaging studies of the SGP.

A large component of program management was the identification and mitigation of risk. As prime contractor, R. B. Toth Associates implemented

3 W. Noel, "Revealing the Lost Codex of Archimedes," TEDxsummit, Doha, April 2012, https://www.ted.com/talks/william_noel_revealing_the_lost_codex_of_archimedes, accessed 17 April 2017.

4 W. A. Christens-Barry, K. Boydston, F. G. France, K. T. Knox, R. L. Easton Jr., and M. B. Toth, "Camera System for Multispectral Imaging of Documents," Proc. SPIE 7249-08 (2009). 
the SGP project under a firm fixed price contract. This placed the financial risk on the prime contractor, including responsibility for all subcontractors, equipment, and logistics costs. To mitigate risk, on 12 December 2008 Toth Associates proposed an initial "Syriac Image Study" with initial multispectral imaging and processing of just a few several sample leaves at the Walters Art Museum in Baltimore, Maryland. ${ }^{5}$ This lower-cost "study phase" during the first quarter of $2009^{6}$ was intended to provide:

1. Characterization of the SGP text and parchment for possible future imaging, digitization, and processing.

2. Technical risk reduction with assessment of multispectral imaging technologies and work processes for possible digital image collection.

3. Objective data to assess the feasibility of future imaging and scholarly study.

Ultimately, this would lead to a presentation of findings and recommendations to the owner by mid-2009 to support disbinding, conservation, and imaging of the entire SGP. This included an assessment of multispectral imaging capabilities, costs, and risks, with a plan for efficient image collection, processing, data management, and scholarly analysis.

The SGP multispectral imaging project built on the advances in technology and work processes from the initial Archimedes Palimpsest program and subsequent imaging of the Waldseemüller 1507 world map, Universalis Cosmographia, and other parchment manuscripts on contract to the Library of Congress. ${ }^{7}$ These advances included not just the imaging and narrowband illumination technology, but also the integration of data and metadata creation and management. The proposed study included imaging and technical assessment of the selected SGP leaves with "[multispectral] imaging of

5 R. B. Toth Associates, Syriac Palimpsest Technical Imaging Study, 12 December 2008.

6 The proposed schedule noted the dates were "all TBR and rather optimistic after the imaging."

7 F. G. France and M. B. Toth, "Spectral Imaging for Revealing and Preserving World Cultural Heritage," paper presented at the 19th European Signal Processing Conference (EUSIPCO '11), Barcelona, Spain, 2011, 1450-54. 


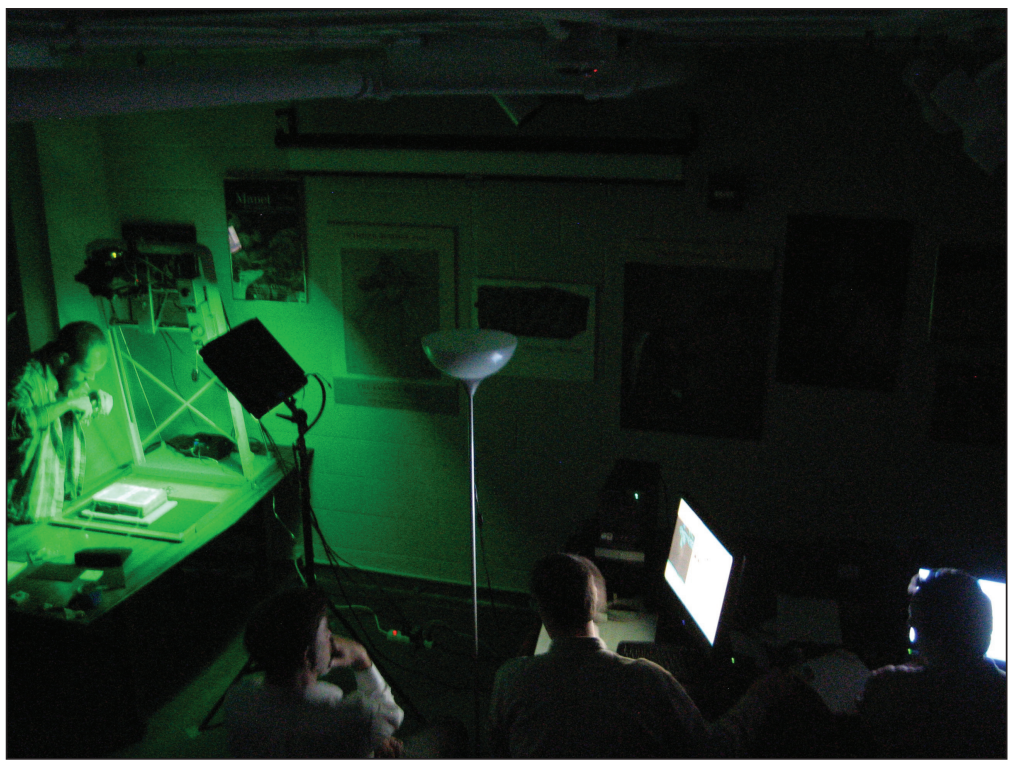

FIGURE 2. Narrowband multispectral imaging system with bound SGP during study phase.

bound exemplar pages using the same LED illumination with at least 12 spectral bands and raking light integrated with an available 39 Megapixel monochrome camera" (fig. 2). To characterize the makeup of the SGP, it also included "spectral characterization using an Ocean Optics spectrometer ... and other nondestructive tests as available."

The goal of multispectral imaging is to render visible to scholars that which had been illegible, through the production of post-processed images. The varied visual acuity of different scholars complicates this task, and had to be considered as part of the program planning and scheduling. Supporting various scholars with different visual acuity and interests can require production of multiple images of the same area, variously processed. The proposed SGP study phase included the following digital image processing and research, building upon that performed in prior projects:

8 R. B. Toth Associates, Syriac Palimpsest Technical Imaging Study. 
1. Standard pseudocolor and Sharpie processing using the Archie 1.0 software. ${ }^{9}$

2. Open processing by individual scientists with various software.

3. Principal component analysis of images collected previously with Stokes color camera (if possible with pattern). ${ }^{10}$

Deliverables for the SGP project were based on those developed for previous projects at the Walters Art Museum and the Library of Congress:

1. 16-bit TIFF images of sample pages with metadata: UV, visible, infrared, raking light

2. Processed images of each sample page with metadata:

a. True color images produced with monochrome visible spectra

b. Pseudocolor images produced with spectra to be determined:

i. Standard pseudocolor with both upper and lower texts displayed in different colors

ii. "Sharpies" with the upper text suppressed, highlighting just the lower text

3. Additional processed images determined through experimentation.

A truly interdisciplinary project requires not just imaging scientists, but also paleographers and humanists. Scholars of medieval Syriac manuscripts are thin on the ground, but at the recommendation of Sebastian Brock, Siam Bhayro flew over from Exeter University to be present during the imaging. He provided needed scholarly support and expertise on the Syriac text that would be revealed by the multispectral imaging and digital processing. His availability on site during the imaging allowed him to study the digital multispectral test images and provided rapid feedback for the imaging team to refine the imaging and digital processing. Bhayro's ability to highlight the text visible with various spectral bands and processing techniques-

9 For a description of pseudocolor and Sharpie processing, see Easton et al., in this issue.

10 R. B. Toth Associates, Syriac Palimpsest Technical Imaging Study. The study of this phenomenon that occurred during the Archimedes Palimpsest imaging led to an important advance in narrow-band multispectral imaging of manuscript fluorescence. 
especially in comparison with the manuscript itself-proved invaluable to developing the techniques and processes needed to image the entire manuscript during the next phase of imaging.

This study phase advanced both scholarship and technology with the following:

1. Bhayro worked with the processed digital images of the leaves of the SGP imaged in March 2009, both in person and with Sebastian Brock in Oxford. They identified several leaves of the Syriac Palimpsest as a Syriac translation of Galen's On Simple Drugs. Bhayro was able to ascertain that the Syriac translation of Galen in the palimpsest was the same as that of Sergius of Rēš 'Aynā, found in British Library Add. MS 14661.

2. Additional research into the Archimedes Palimpsest images and imaging experiments on the SGP led to important narrow-band multispectral imaging developments, which optimized the capture of information-rich fluorescence from the parchment at certain short wavelengths that was not visible in reflected light alone.

\section{Multispectral Imaging of the Entire Palimpsest}

The experience, tools, and methodologies gleaned from the study phase enabled the development, management, and integration of successful imaging for the entire SGP. This was accomplished with the integration of data, metadata, work processes, and personnel with various talents into an effective team. Upon completion of the successful study phase, the Walters Art Museum contracted for the multispectral imaging and digital processing of all 240 sides of the disbound Syriac Palimpsest one year later. Based upon experience gained during the SGP test imaging in the spring of 2009, R. B. Toth Associates provided the Walters with a follow-on proposal to image and digitally process the entire disbound Syriac Palimpsest in 2010. This included a plan and schedule for imaging and initial digital processing on site at the Walters to rapidly provide a full product. As before, Toth Associ- 


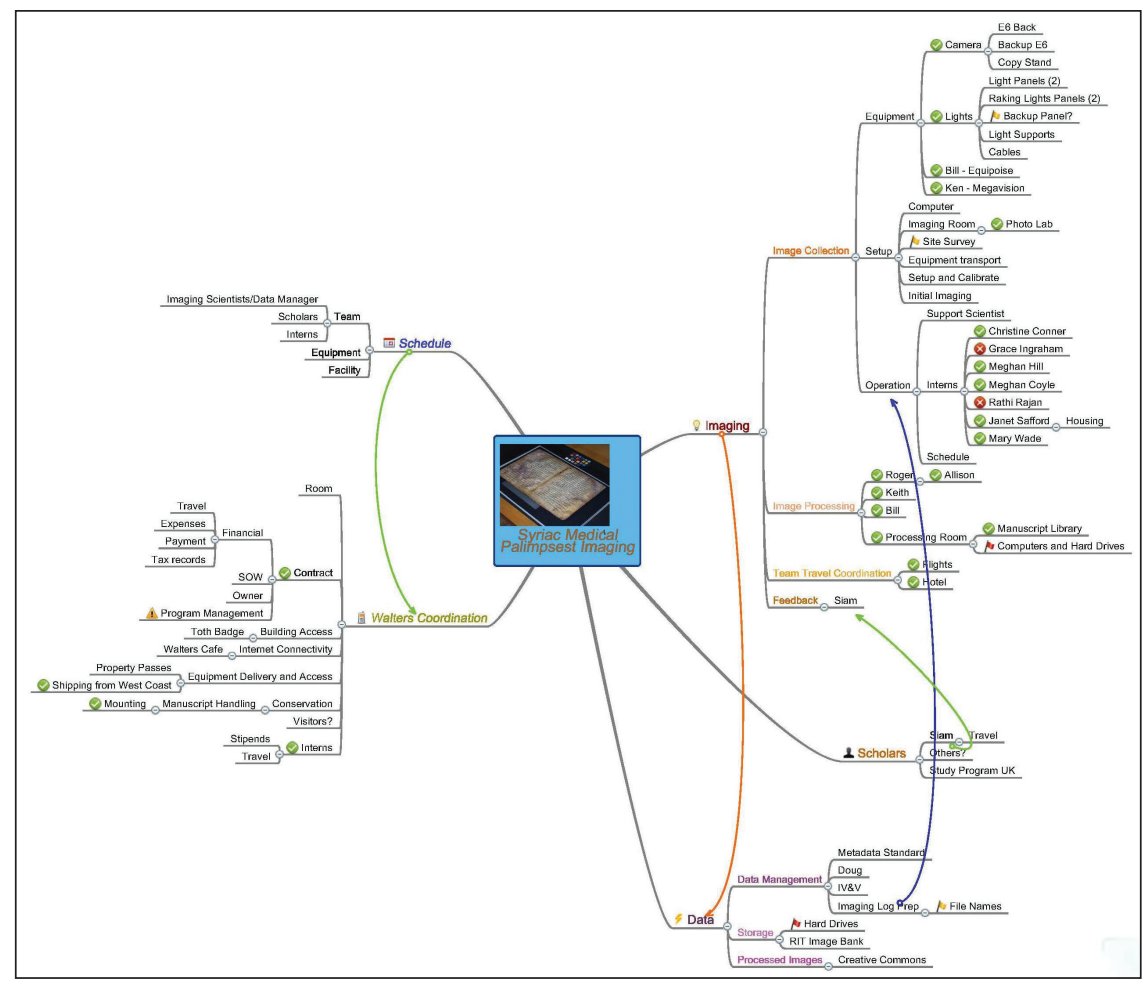

FIGURE 3. Schematic of planning for multispectral imaging of entire SGP.

ates planned for Bhayro to travel to the Walters for on-the-spot feedback. This allowed the team to adjust parameters and perform any additional imaging possible while the equipment and personnel were still on site. Most importantly, the full final data product was to be hosted online to be made available for research. All this was planned to bring together all the needed activities and tasks for completion within the fixed budget and schedule (fig. 3).

The goal of this phase of the SGP project was to "spectrally image all leaves of the Syriac Palimpsest, process the images to reveal the undertext, and make the product available on a Web server and via hard drives within a two-month period early in 2010." The contract included delivery of a digital product with a complete archival package of images with documentation 
and full metadata. This data set was based on the archive and metadata model used for the Archimedes Palimpsest:

The Syriac Palimpsest Digital Product provides all the digital information available on the Syriac Palimpsest in a single digital data set, with a standard structure. Its purposes are twofold:

1. Serve as the authoritative digital data set of images in a standardized format that meets the needs of users, information providers, archives, and libraries.

2. Offer a standard product sustainable by users to which current or future contributors can add additional standardized information (e.g., alternate texts, image analyses or conservation information).

Following contract initiation and development of a program plan and schedule, conservators worked to disbind, stabilize, and mount the SGP leaves for imaging. The same multidisciplinary team that worked on the study phase supported multispectral imaging, processing, and initial scholarly evaluations and studies from 22 February to 12 March 2010 in the Walters Art Museum. A team of volunteer interns performed the actual imaging to allow the image scientists to focus on the digital image processing in another area of the museum. Meghan Wilson (née Hill), Meghan Coyle, Mary Ware, Janet Safford, and Christine Conner served as spectral imaging interns responsible for the efficient operation of the then-leadingedge digital spectral imaging system. They conducted the imaging in a lower corner of the Walters, with the data transferred by hand-carried "sneakernet" hard drives to the image scientists in the opposite upper corner of another wing of the building.

The successful imaging of the SPG was in large part due to the interns' diligence and dedication to this project as volunteers, and to the extensive Walters Art Museum conservation support. Their combined effort ensured a smooth flow of palimpsest leaves for imaging, with good recordkeeping and imaging logs (fig. 4). This steady imaging workflow served as the basis for subsequent multispectral imaging projects, including David Living- 


\begin{tabular}{|c|c|c|c|c|c|}
\hline \multicolumn{4}{|c|}{1 folio_id folio_name shot_set_id set_name } & \multirow{2}{*}{$\begin{array}{l}\text { shot_time } \\
2010-03-03 \text { 11:43:00-0500 }\end{array}$} & \multirow{2}{*}{ comment } \\
\hline 248187 & $183 r-186 v$ & 931 & $183 r-186 v \_A$ & & \\
\hline 249188 & $183 \mathrm{v}-186 \mathrm{r}$ & 936 & $183 v-186 r \_A$ & 2010-03-03 11:51:00-0500 & \\
\hline 250189 & $184 r-185 v$ & 941 & $184 \mathrm{r}-185 \mathrm{v} \_\mathrm{A}$ & 2010-03-03 11:58:00-0500 & \\
\hline 251190 & $184 \mathrm{v}-185 \mathrm{r}$ & 946 & $184 v-185 r \_A$ & $2010-03-03 \quad 12: 06: 00-0500$ & undertext with UV \\
\hline 252225 & $223 r-226 v$ & 1121 & 223r-226v_A & 2010-03-03 13:37:00-0500 & \\
\hline $253^{\prime} 226$ & $223 v-226 r$ & 1126 & $223 v-226 r \_A$ & $2010-03-03 \quad 13: 42: 00-0500$ & \\
\hline 2541 & $001 r-004 v$ & 3 & $001 r-004 v \_c$ & 2010-03-03 13:49:00-0500 & Set \#1 taken with $10 \mathrm{sec}$ of UV light. \\
\hline $255 \overline{7}$ & $007 r-014 v$ & 32 & $007 r-014 v \_B$ & $2010-03-03 \quad 13: 57: 00-0500$ & Set \#1 taken with $10 \mathrm{sec}$ of UV light. \\
\hline 25616 & $015 v-022 r$ & 77 & $015 v-022 r \_B$ & 2010-03-03 14:04:00-0500 & Set \#1 taken with $10 \mathrm{sec}$ of UV light. \\
\hline $257^{\prime} 17$ & $016 \mathrm{r}-021 \mathrm{v}$ & 82 & $016 r-021 v \_B$ & $2010-03-03 \quad 14: 12: 00-0500$ & Set \#1 taken with $10 \mathrm{sec}$ of UV light. \\
\hline $258 / 23$ & $023 r-030 v$ & 112 & 023r-030v_B & $2010-03-03 \quad 14: 20: 00-0500$ & Set \#1 taken with $10 \mathrm{sec}$ of UV light. \\
\hline $259^{\prime} 41$ & $040 r-045 v$ & 202 & $040 r-045 v \_B$ & 2010-03-03 14:29:00-0500 & Set \#1 taken with $10 \mathrm{sec}$ of UV light. \\
\hline 260108 & $103 v-106 r$ & 537 & $103 v-106 r \_B$ & 2010-03-03 14:38:00-0500 & Set \#1 taken with $10 \mathrm{sec}$ of UV light. \\
\hline $261 / 2$ & $001 v-004 r$ & 7 & $001 v-004 r \_B$ & 2010-03-03 14:51:00-0500 & UV at 10 seconds, reshoot, system error \\
\hline $262 / 2$ & $001 v-004 r$ & 8 & $001 v-004 r \_c$ & 2010-03-03 14:59:00-0500 & reshoot of reshoot after system error, restarted system \\
\hline $263 / 4$ & $002 v-003 r$ & 17 & $002 v-003 r_{-} B \mathrm{~B}$ & 2010-03-04 11:11:00-0500 & 5.6 Color wheel. Refocus and slight height change \\
\hline$2 6 4 \longdiv { 4 }$ & $002 v-003 r$ & 18 & $002 v-003 r \_c$ & 2010-03-04 11:13:00-0500 & B was run on set 2 before set one \\
\hline $265: 216$ & $214 \mathrm{v}-221 \mathrm{r}$ & 1078 & $214 v-221 r \_c$ & 2010-03-04 11:20:00-0500 & 5.6 color wheel for set 2. Imaged fragment. \\
\hline $266^{\prime} 10$ & $008 v-013 r$ & 47 & $008 v-013 r \_B$ & 2010-03-04 11:31:00-0500 & 5.6 on set 2 . File mislabled. \\
\hline 26712 & $009 v-012 r$ & 57 & $009 v-012 r_{-} B \mathrm{~B}$ & 2010-03-04 11:45:00 -0500 & shot set B under 5.6 . \\
\hline 26814 & $010 \mathrm{v}-011 \mathrm{r}$ & 67 & 010v-011r_B & 2010-03-04 11:48:00-0500 & \\
\hline 26914 & $010 \mathrm{v}-011 \mathrm{r}$ & 68 & $010 v-011 r+c$ & 2010-03-04 11:53:00-0500 & shot with 5.6 for set 2 \\
\hline 27019 & $017 r-020 v$ & 92 & $017 r-020 v \_B$ & 2010-03-04 12:04:00-0500 & shot set 2 on 5.6 . \\
\hline 27121 & $018 r-019 v$ & 102 & $018 \mathrm{r}-019 \mathrm{v} \_\mathrm{B}$ & 2010-03-04 12:10:00-0500 & shot set 2 with 3.5 for the color wheel. \\
\hline 27222 & $018 \mathrm{v}-019 \mathrm{r}$ & 107 & 018v-019r_B & 2010-03-04 12:17:00-0500 & 5.6 for set 2 \\
\hline 27325 & $024 r-029 v$ & 122 & $024 r-029 v \_B$ & $2010-03-0412: 23: 00-0500$ & second set shot with 5.6 \\
\hline 27427 & $025 r-028 v$ & 132 & $025 r-028 v \_B$ & $2010-03-04 \quad 12: 37: 00-0500$ & color wheel imaged with 5.6 \\
\hline 27529 & $026 r-027 v$ & 142 & $026 r-027 v_{-}^{-} B$ & 2010-03-04 12:45:00-0500 & color wheel run under 5.6 . \\
\hline$2 7 6 \longdiv { 2 7 }$ & $025 r-028 v$ & 133 & 025r-028v_c & $2010-03-0510: 30: 00-0500$ & Set \#2 shot at F 5.6. Glow in bottom right corner. Out \\
\hline $14, i n$ & & 2010 & & & \\
\hline
\end{tabular}

FIGURE 4. Excerpt of SGP imaging log.

stone's Diaries ${ }^{11}$ and the palimpsests in St. Catherine's Monastery in the Sinai. ${ }^{12}$ This included development of standard checklists, planning, and organization of each day's imaging, pre-planned file naming conventions, and even addressing factors such as environmental controls and restrictions on personnel in the imaging room. The imaging team found it had to avoid deviating from the imaging plan, as this introduced opportunities for mistakes that could corrupt the data set. In particular, the team tried to minimize ad hoc decisions that could have an impact on the system efficiency and downstream work processes, especially if not considered in the context of the full system.

Coordination with and support by the conservation team, led by Walters manuscripts conservator Abigail Quandt, proved critical to ensuring the manuscript leaves were ready for imaging after conservation. Linda Owen

11 A. Wisnicki and M. B. Toth, “The David Livingstone Spectral Imaging Project," in David Livingston: Man, Myth and Legacy, ed. S. Worden (Edinburgh: National Museums Scotland, 2012), 154-68.

12 Fr. J. Sinaites and M. B. Toth, "Spectral Imaging at the Library of St. Catherine's Monastery Reveals Ancient Texts [video]," Library of Congress, 19 November 2012, http://www. loc. gov/preservation/outreach/tops/ancient_text/ancient_text. html, accessed 12 April 2017. 
disbound the palimpsest and stabilized the leaves in mats for imaging. Vincent Carney, a contract conservator, handled the palimpsest leaves during imaging and monitoring the room environment-always an issue in an older part of the museum during the change of seasons and environmental control settings. Having a trained conservator in the imaging room both reduced risk to the object and provided an important triple check of the imaging setup and verification that the correct leaf was being imaged. Bhayro's availability also allowed for consensus in identifying leaves with minimal identifying marks and the key areas of interest. This teamwork helped ensure a smooth workflow and quality check, especially with identification, orientation, and positioning of the object.

Overall management of the SGP imaging and processing focused on avoiding bottlenecks across the imaging system, including in the data flow, data replication, image processing, and production of the image product. This spanned the activities from the day-to-day conservation and handling of the palimpsest leaves through the imaging to the image processing and data management. Having separate work locations for the imaging and processing proved critical to the efficient parallel work. Imaging in a controlled location by trained and dedicated imagers allowed the scientists to collaborate on digital processing in a separate location without impacting the imaging. Ultimately all these activities had an impact on the Walters Art Museum as the host institution, but the team tried to keep this to a minimum with pre-clearance and badging of personnel and well-planned equipment handling and setup.

One of the lessons noted after the imaging and digital processing was the need for a formal quality control check of the image files as part of the work processes. The data pipeline required frequent copying and transmission of data for the image scientists and the final data set. This offered opportunities for mistakes that could lead to data corruption. To be effective, quality control needed to be timely, with effective feedback for reimaging if needed, preferably with data checking using automated tools, checksums, and file checking scripts, as well as validation of images for focus, illumination, and data completeness (fig. 5).

Doug Emery managed the image data, developed the image product, and hosted the data online for free access on digitalgalen.net. The SGP 


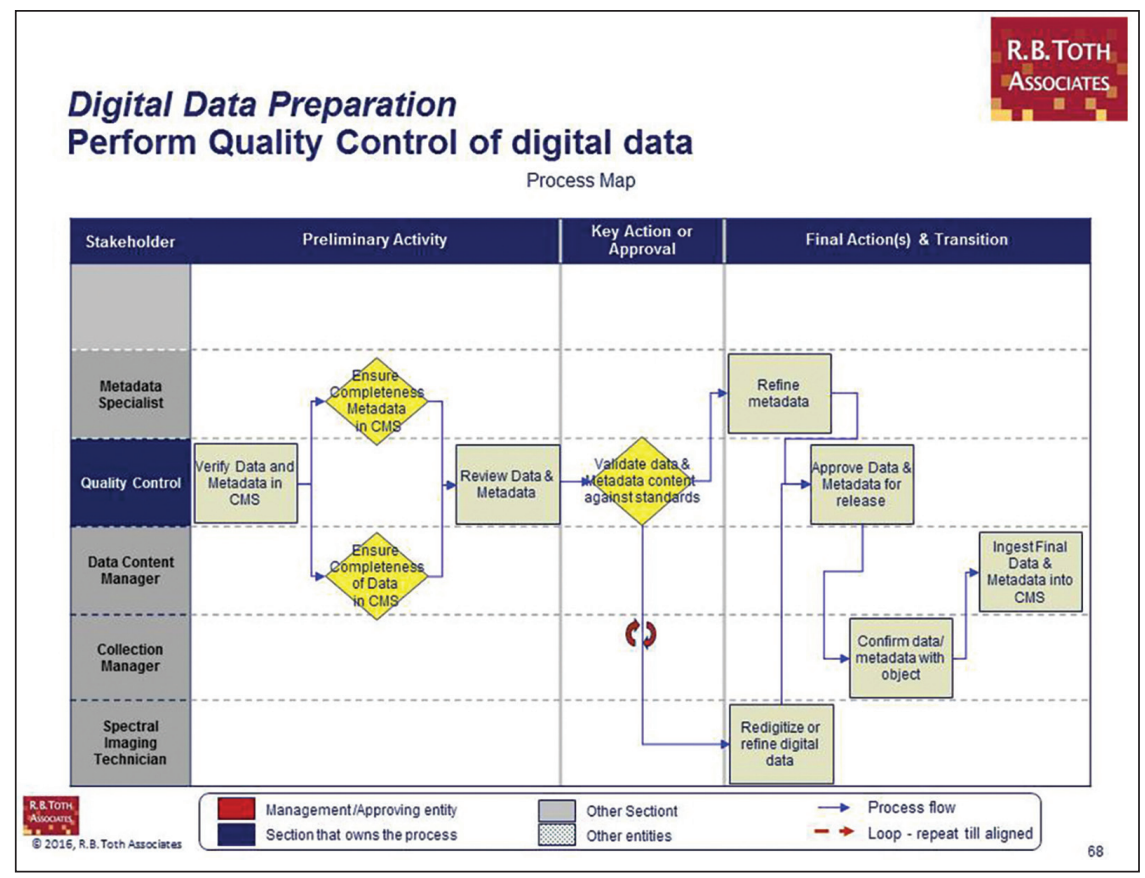

FIGURE 5. Quality control process map.

project planning and scheduling had to ensure completion of a spectral image product that included standardized multispectral data with the data structure to ensure digital preservation of, and access to, all the captured and processed images. Metadata collection was an integrated part of the imaging. ${ }^{13}$ After imaging and processing was completed, Emery collated the imaging logs with other required metadata to generate complete metadata records for raw and processed images, and assemble the final data archive. Since full metadata was captured with the image data and the interns kept excellent imaging logs (as shown in fig. 4), Emery did not have to match metadata to the images after imaging and processing as he did in

13 D. Emery, M. B. Toth, and W. Noel, "The Convergence of Information Technology and Data Management for Digital Imaging in Museums," Museum Management and Curatorship 24, no. 4 (2009): 337-56. 
the Archimedes project. Upon completion of the SGP multispectral imaging project within cost and schedule, about 300 GB of SGP multispectral data and metadata was hosted online for global access and research at http://digitalgalen.net/.

\section{Independent Study of the SGP Spectral Images}

While the formal SGP project was completed with the hosting of all the images and metadata online in 2010, this was only the beginning of the scholarly research and discovery. Collaboration started in May 2012, when a team of European scholars met at the University of Manchester for a workshop to begin a collaborative approach to transcribing the texts, with initial transcriptions of several leaves. They included Peter Pormann and John Healey from Manchester, Grigory Kessel from Germany, Siam Bhayro from Exeter, and Robert Hawley and Jimmy Daccache from Paris. Michael Toth joined them as a volunteer and provided an introduction to the image data online, the different processed images, and methods for viewing and comparing the images. They were also joined by Carol Burrows and other digitization specialists from the University of Manchester Centre for Heritage Imaging and Collection Care and Bill Sellers and other imaging scientists at the University of Manchester. They had arranged to have the SGP data mirrored in the United Kingdom, and some scholars had also stored the data locally on hard drives. In addition, as part of his independent research, former Massachusetts Institute of Technology (MIT) student Greg Echelberger tiled the Syriac Galen Palimpsest image data to allow zooming and scanning of the images without having to download the full TIFF files.

The scholars accessed the Syriac Galen leaves of interest by downloading individual processed images of interest from the web or pulling them up from their hard drives. During the Manchester workshop and a follow-on Paris workshop in November 2012, Toth supported them as they studied magnified single pseudocolor or Sharpie images of specific leaves projected on a screen, and then flicked back and forth between the images and scrolled around the images to get better insight into difficult texts (fig. 6). The 


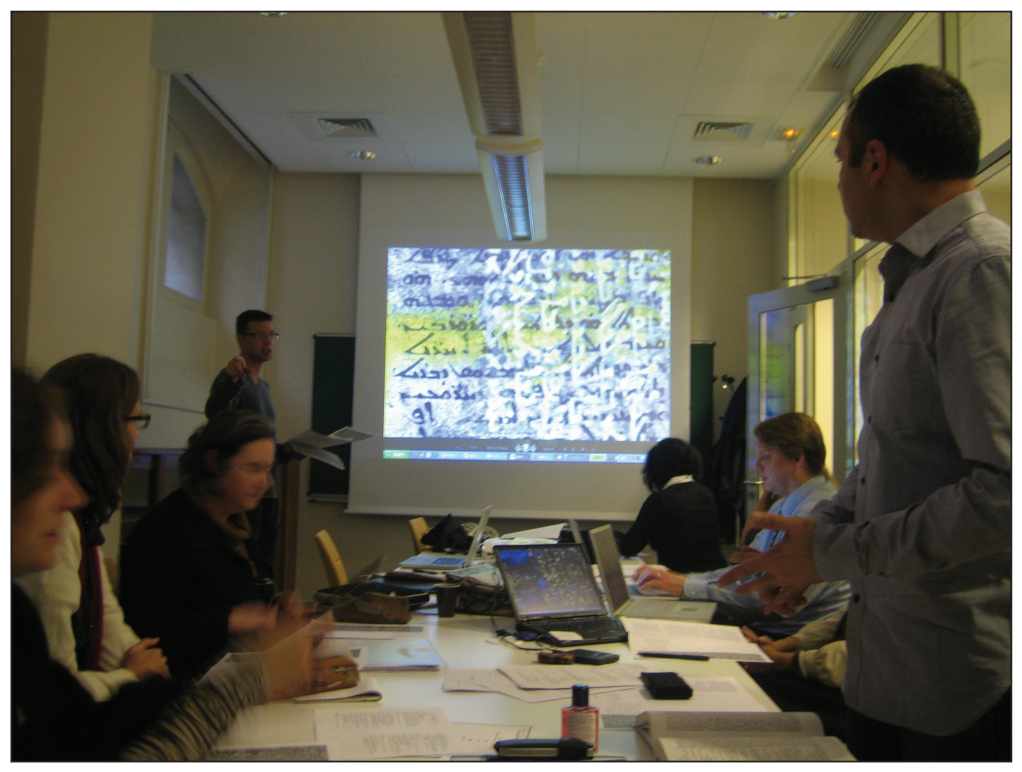

FIGURE 6. Scholars' collaborative study of processed images during workshop.

TIFF images are up to $112 \mathrm{MB}$ in size, making it difficult for them to download and manipulate multiple images of the data set. During the workshop they moved through leaves of interest by reviewing the processed images of choice, highlighting challenging areas as they arose and then rapidly moving on. They then reviewed the enhanced process images individually and shared their insights by email. They found that collaboration was essential to their progress.

The scholars began their effort with a comparison of the SGP text with the Sergius text in British Library (BL) Add. MS 14661, and with Hunayn's later Syriac translation of Galen's Simples. They found that comparison with the BL manuscript was extremely useful, although their collaboration in this endeavor was hampered by the copyright restrictions then imposed on images of the manuscript.

The scholars noted that although there were approximately eighty pages of "really tough stuff" that might require additional image processing support in time, they did not feel they needed additional image processing to 
make immediate progress. In general, realizing the large amounts of data they needed to characterize, they avoided getting bogged down on a particular leaf and focused only on especially critical text for further processing. The results of this initial workshop were published in two publications, one at the end of 2012 and another in early 2013. As a result of this characterization, they noted the SGP is an extremely important Syriac text that expands knowledge of Galen significantly. ${ }^{14}$

A set of multispectral images can yield a myriad of processed images representing different areas of interest. With free access to the captured spectral images, standardized file structures, and available image processing tools, some of the SGP scholars were interested in producing their own digitally processed images that addressed their needs. Some of the scholars performed their own image processing with Bill Christens-Barry's open-source ImageJ tool plugin to tailor their own processed images that support their research. With the captured images and some relatively nontechnical training, some scholars were able to follow straightforward "recipes" to use principal component analysis (PCA) and other computer processing techniques with ImageJ to produce useful images from combinations of various spectral bands. This complemented their work with scientists and digitization experts to optimize additional digital processing to highlight key areas of interest.

In a related effort that tapped the rich array of online SGP data, Robert Hawley developed the Floriental Project with European Research Council support to: "1) publish textual editions of the main Syriac 'herbals' (of which the two most important have never been fully edited), and 2) to bring together specialists in Greek, Syriac, and Arabic/Islamic Medicine in order to exploit most fully and contextual these little known Syriac productions."15 Over the course of this project, the scholarly team supported five international scholarly conferences. During the November 2013 Floriental Paris Conference, "From Babylon to Baghdad: Toward a History of the 'Herbal' in the Near East," the scholarly team and program manager met again to

14 S. Bhayro and S. Brock, "The Syriac Galen Palimpsest and the Role of Syriac in the Transmission of Greek Medicine in the Orient," Bulletin of the Jobn Rylands University Library of Manchester (ed. R. David) 89, suppl. (2012/2013): 25-43.

15 R. Hawley, “The FLORIENTAL Project, Mid-Term Activity Report,” ERC-2010-StG 263783 Floriental, April 2014. 
assess future opportunities for independent collaboration and research. They discussed the potential for a conference at the University of Pennsylvania to bring together the scholarly, scientific, imaging, and data personnel, which finally came to fruition in April 2016. The SGP data was also tapped by an online forum for the study of Islamic culture for its insights into the transfer of medical knowledge in the Middle East. ${ }^{16}$ In what may have been a first for medieval manuscripts-and definitely for a Syriac manuscript - the New York Times cited the scholars' research in an article on the front page of the Science section. ${ }^{17}$

One of the key contributions of this continued independent research into the SGP was the discovery by Grigory Kessel of additional leaves from the SGP. When he and Michael Toth conducted a hands-on review of the actual palimpsest, Kessel realized the similarity to a leaf at the Harvard University Houghton Library he had just examined (fig. 7). Then, after reviewing Sebastian Brock's catalog of Syriac palimpsests in St. Catherine's Monastery in the Sinai, Dr. Kessel noted one entry that alluded to a medical undertext. Upon further inspection, this proved to indeed be a leaf from the SGP. After spectral imaging of both the Harvard and Sinai leaves, the owner supported a continued catalog search by Kessel, which turned up three more leaves in the Vatican Library (fig. 8) and one in the Bibliothèque nationale de France (fig. 9). These were subsequently also spectrally imaged. In total, Kessel found that in addition to the bound 225 parchment leaves in the owner's private library, there are six leaves in the following institutions: ${ }^{18}$

- St. Catherine's Monastery Library: Syriac New Finds Fragment 65

- Vatican Apostolic Library: Vat. Sir. 647, fols. 38 and 39; Vat. Sir. 623, fol. 227

- National Library of France: BnF syr. 382

- Houghton Library: MS Syriac 172

16 A. Das, R. M. Rosen, and M. B. Toth, "The Syriac Galen Palimpsest: Digital Recovery of a Missing Link Between Greek and Islamic Science,” Mizan Project, 3 March 2016, http:// www.mizanproject.org/the-syriac-galen-palimpsest, accessed 12 March 2017.

17 M. Schrope, “Medicine’s Ancient Roots,” New York Times, 2 June 2015, p. D1.

18 G. Kessel, "Membra disjecta sinaitica I: A Reconstitution of the Syriac Galen Palimpsest," Manuscripta Graeca et Orientalia 243 (2016): 469-96. 


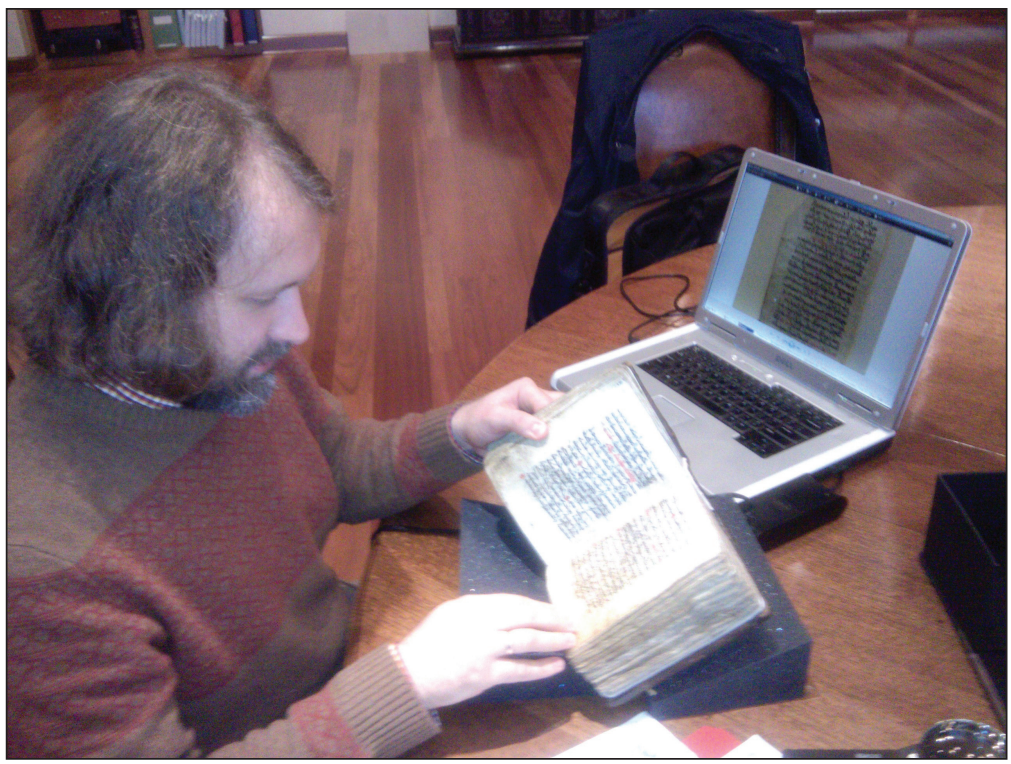

FIGURE 7. Grigory Kessel comparing bound SGP with image of Harvard leaf MS Syriac 172.

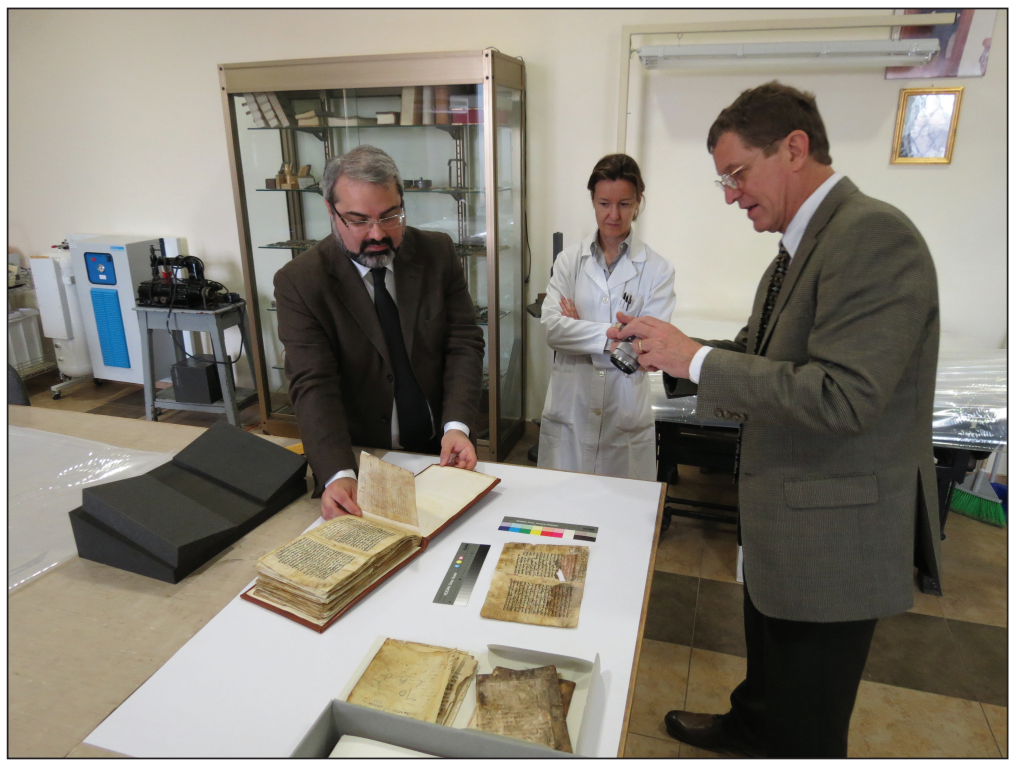

FIGU RE 8. Examination of Vatican Library SGP leaves Vat. Sir. 647 fols. 38 and 39 and 623 fol. 227. 


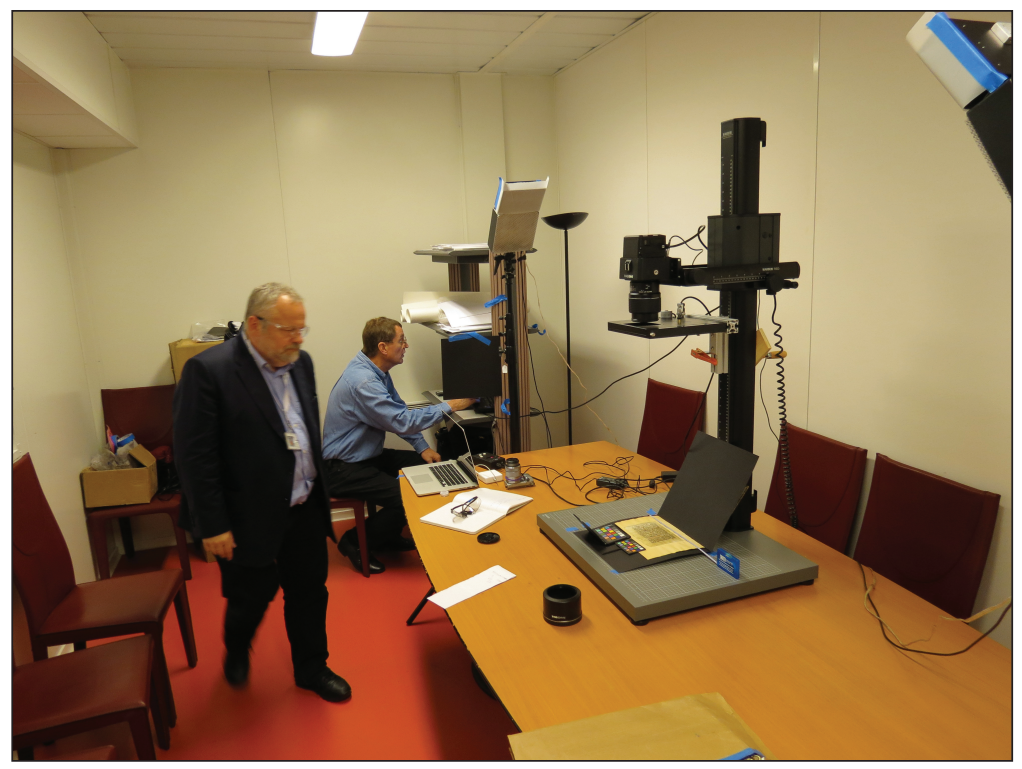

FIGURE 9. Multispectral imaging of SGP leaf BnF syr. 382 in the Bibliothèque nationale de France.

With the gracious release of the spectral images under Creative Commons license by each of the institutions, and support from the University of Pennsylvania Libraries and the Schoenberg Institute of Manuscript Studies, all these images were added to the online SGP data set. ${ }^{19}$ Additional imaging of the bound manuscript with the latest generation of multispectral imaging equipment provided the scholars with additional information from the leaves. This included imaging with larger-format 60- to 100-megapixel cameras with high dynamic range, additional filtering of fluorescent images, new illumination, and longer exposures (fig. 10). With further research into all the leaves, Kessel concluded the bound manuscript had originally been

19 The Holy Monastery of St. Catherine's of the Sinai, the Bibliotheca Apostolica Vaticana, the Bibliothèque nationale de France, and Harvard University Houghton Library not only provided access to their collections for spectral imaging, but were also generous in granting Creative Commons licenses to share the digital data for free access along with that of the anonymous owner of the codex on www.digitalgalen.net. 


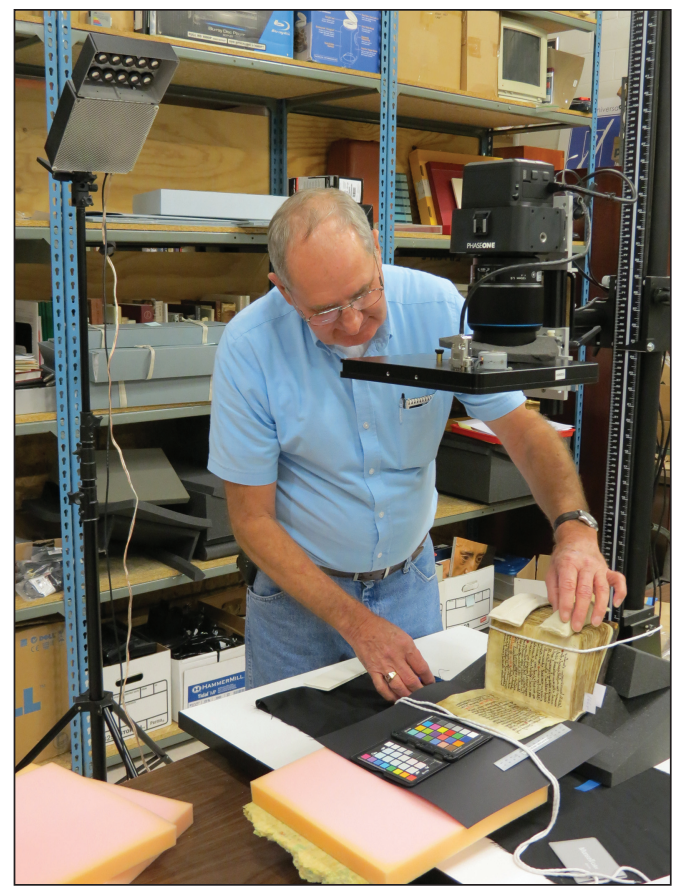

FIGURE 10. Reimaging bound SGP with newgeneration multispectral imaging system.

in the St. Catherine's Monastery Library. The manuscript itself is believed to have been removed from the Sinai library in the latter half of the nineteenth or early twentieth century, and first offered for sale in Europe in 1922. ${ }^{20}$ Now, for the first time since it was removed from the library, the manuscript is digitally reunited online for global research.

\section{Conclusions}

Only with effective integration of standard work processes, scheduling, management, and planning can institutions and projects really tap the

20 Kessel, "Membra disjecta sinaitica." 
potential offered by multispectral imaging to provide new insights into fragile and at-risk objects. Since the SGP project, integrated multispectral imaging systems have been used to reveal new information about previously unseen texts and drawings. Institutions such as Duke University and the University of Manchester John Rylands Library have implemented effective program management as they conduct multispectral imaging with their own systems to support cross-disciplinary collaboration. Other institutions such as KU Leuven, University of California, Berkeley, University College London, and the Getty Museum and Conservation Institute have used a multispectral imaging system to support specific projects, requiring effective planning, cost, and schedule. New data-sharing constructs and continued standardization are enhancing the ability to share image data across institutions and information providers, including the International Image Interoperability Framework. ${ }^{21}$

The development of standardized advanced imaging systems, work processes, and training for the application of scientific techniques to objects of cultural heritage has benefited from the pioneering management and planning techniques adapted for the SGP. With global online storage and free access to standard multispectral images, the SGP image data and metadata should be available to support continued independent research well into the future. The SGP itself was rebound and stored in environmentally controlled conditions in the United States, but the information from the manuscript is available around the globe. Only with these data freely available - thanks to the sharing by multiple institutions - is it possible to digitally reunite manuscripts and palimpsests like the SGP, and to add substantially and responsibly to the sum of knowledge.

\section{Acknowledgments}

While this paper reflects the views of a single author, the successes of imaging programs such as the SGP project rely on the expertise and dedication

21 IIIF Quick Start Guide, International Image Interoperability Framework, 2017, http://iiif. io/technical-details/\#iiif-quick-start-guide, accessed 12 April 2017. 
32 | Journal for Manuscript Studies

of international teams of professionals. All contributed to this project in their own inimitable way: scholars, conservators, interns, scientists, engineers, librarians, curators, data administrators and managers, digitization professionals, and many others. Their work was dependent on the generosity of the owner of the SGP, who continues to support advances in the fields of cultural heritage imaging and data access. Not only has his support allowed significant technical development for other projects, but his focus on efficiencies and scope throughout the project has also advanced program management in the execution of digital cultural heritage projects. 